\title{
Excess mortality due to indirect health effects of the 2011 triple disaster in Fukushima, Japan: a retrospective observational study
}

\author{
Tomohiro Morita, 1,2 Shuhei Nomura, ${ }^{3,4}$ Masaharu Tsubokura, 1,2 Claire Leppold, 5,6 \\ Stuart Gilmour, ${ }^{4}$ Sae Ochi, ${ }^{1}$ Akihiko Ozaki, ${ }^{6,7}$ Yuki Shimada, ${ }^{6}$ Kana Yamamoto, ${ }^{6}$ \\ Manami Inoue, ${ }^{8}$ Shigeaki Kato, ${ }^{9,10}$ Kenji Shibuya, $^{4}$ Masahiro Kami ${ }^{2,11}$
}

\begin{abstract}
- Additional material is published online only. To view please visit the journal online (http://dx.doi.org/10.1136/ jech-2016-208652).
\end{abstract}

For numbered affiliations see end of article.

\section{Correspondence to} Dr Tomohiro Morita, Soma Central Hospital, 3-5-18, Okinouchi, Soma City, Fukushima, 976-0016, Japan; t. morita526@gmail.com

Received 14 November 2016 Revised 7 August 2017 Accepted 8 August 2017 Published Online First 22 August 2017

\section{CrossMark}

To cite: Morita T, Nomura $S$, Tsubokura M, et al. J Epidemiol Community Health 2017:71:974-980.

\begin{abstract}
Background Evidence on the indirect health impacts of disasters is limited. We assessed the excess mortality risk associated with the indirect health impacts of the 2011 triple disaster (earthquake, tsunami and nuclear disaster) in Fukushima, Japan.

Methods The mortality rates in Soma and Minamisoma cities in Fukushima from 2006 to 2015 were calculated using vital statistics and resident registrations. We investigated the excess mortality risk, defined as the increased mortality risk between postdisaster and predisaster after excluding direct deaths attributed to the physical force of the disaster. Multivariate Poisson regression models were used to estimate the relative risk (RR) of mortality after adjusting for city, age and year. Results There were 6163 and 6125 predisaster and postdisaster deaths, respectively. The postdisaster mortality risk was significantly higher in the first month following the disaster (March 2011) than in the same month during the predisaster period (March 2006-2010). RRs among men and women were 2.64 (95\% Cl 2.16 to 3.24$)$ and $2.46(95 \% \mathrm{Cl} 1.99$ to 3.03), respectively, demonstrating excess mortality risk due to the indirect health effects of the disaster. Age-specific subgroup analyses revealed a significantly higher mortality risk in women aged $\geq 85$ years in the third month of the disaster compared with predisaster baseline, with an RR $(95 \% \mathrm{Cl})$ of 1.73 (1.23 to 2.44).

Conclusions Indirect health impacts are most severe in the first month of the disaster. Early public health support, especially for the elderly, can be an important factor for reducing the indirect health effects of a disaster.
\end{abstract}

\section{INTRODUCTION}

Unprecedented ageing societies, coupled with increasing disaster risks due to climate change and political and economic instability, ${ }^{12}$ make the management of disaster risk a public health issue in terms of prevention, preparation, response, recovery and reconstruction. ${ }^{3}$ This is because the elderly are particularly susceptible to health risks in disaster settings. ${ }^{4}$ For example, the elderly often face a higher mortality risk than younger populations in disaster settings, as seen in the HanshinAwaji earthquake and the Chicago heat wave, both in $1995 .^{5}$ In order to develop effective design and delivery of public health countermeasures against the health impact of disasters in ageing populations, it is essential to understand actual health impacts and their potential risk factors. ${ }^{6}$

The Great East Japan Earthquake, ensuing tsunami and nuclear disaster (hereinafter referred to as the triple disaster), which occurred on 11 March 2011, is a powerful example of a disaster that occurred in a rapidly ageing society. Residents of Soma and Minamisoma cities, located around $10-45 \mathrm{~km}$ north of the Fukushima Daiichi Nuclear Power Plant (see online supplementary figure S1), experienced substantial health consequences from the triple disaster. More than 1000 residents died from direct injuries from the earthquake and tsunami. The disaster also inflicted serious damage to community healthcare systems, resulting in various health consequences. For example, mass evacuation following the disaster strained essential health services and infrastructure and disrupted social capital and networks. ${ }^{7}$

After the nuclear disaster, mandatory evacuation zones were issued on 12 March 2011 for the $20 \mathrm{~km}$ radius surrounding the plant, and voluntary evacuation zones were additionally put into place for the $20-30 \mathrm{~km}$ radius. As a result, the population of the study area dropped from its predisaster level of nearly 100000 to 40000 within a month of the triple disaster. ${ }^{8}$ Five of the eight emergency hospitals in the district closed after the disaster because of forced evacuation or workforce shortage.?

The health effects of natural and man-made disasters can be both direct and indirect. ${ }^{9}$ The direct health effects of a disaster are defined as external causes such as traumas and burns that can be attributed directly to the disaster. ${ }^{10}$ Elderly people are at greater risk of increased direct mortality after a disaster. ${ }^{11}$ In the case of Hurricane Katrina in 2005 in the USA, approximately $75 \%$ of all direct mortality in New Orleans occurred among the elderly, who represented only $15 \%$ of the city's total population before the disaster. ${ }^{12}$ The high vulnerability of the elderly to direct disaster impacts could be due to their impaired physical mobility, diminished sensory awareness and pre-existing health conditions. ${ }^{13}$ It is equally important to recognise indirect health effects. Major disasters damage primary healthcare systems and food and water supplies, and cause displacement by evacuation and relocation. ${ }^{1415}$ Previous studies have reported indirect health effects such as increases in the mortality 
risk of cardiovascular diseases ${ }^{16}$ or infectious diseases ${ }^{17}$ after disasters. A report on Hurricane Katrina suggested that indirect psychological health effects of disaster might be implicated in the persistent increase in mortality observed for at least 6 months after Hurricane Katrina in $2006 .{ }^{18}$ Elderly people can also be at greater risk of indirect health effects of disasters due to disruption to ongoing medical care or aggravation of medical conditions; for example, older age was reported to be a risk factor of the disruption of access to medical care after Typhoon Haiyan in 2013. ${ }^{19}$ Disasters can, therefore, exert powerful influences on individual vulnerability to physical and psychological stress, and may also impact health. ${ }^{20}$

However, evidence on the indirect impacts of disasters is limited, ${ }^{21}$ partly because they are, by definition, not directly measurable and partly because it is difficult to prove an indirect causal relationship between postdisaster mortality and morbidity as time passes. The major objectives of the present study were twofold: (1) to assess the excess mortality risk due to the indirect health impacts of the triple disaster in Soma and Minamisoma cities in Fukushima; and (2) to identify the postdisaster risk periods over a multiyear follow-up period and populations at risk of the indirect health effects.

\section{METHODS}

\section{Data sources}

We used vital registration records from a national survey between January 2006 and December 2015 (predisaster: 2006-2010; postdisaster: 2011-2015). Secondary use of the vital registration records was approved by the Ministry of Health, Labour and Welfare in compliance with the Statistics Act. Mortality data were classified by age, sex and cause of death in the International Classification of Diseases and Health-Related Problems, 10th Revision (ICD-10), for each month during the study period. Population data were obtained from the Basic Resident Registers-the nationwide resident-registry network administrated by municipality unit (city/town/village).

\section{Sample selection}

We defined a 'direct death' as a death attributed to external causes, primarily the physical forces of the triple disaster. ${ }^{22} 23$ We considered the following causes of death that occurred in March 2011 to be direct deaths due to the disaster: S00-S09 (injuries to the head), S12 (fractures of neck), S20-S29 (injuries to the thorax), T00-T07 (injuries involving multiple body regions), T14 (injuries of unspecified body region), T29 (burns and corrosions of multiple body regions), T71 (asphyxiation) and T79 (certain early complications of trauma). We additionally considered T75.1 (drowning) that occurred on the disaster date as direct deaths. Our data included no mortality due to exposure to forces of nature (X30-X39).

\section{Inclusion and exclusion criteria}

All mortality data from Soma City and Minamisoma City, Fukushima Prefecture, Japan, in 2006-2015 were eligible for inclusion in the study. In order to investigate the indirect health effects of the triple disaster, we compared the excess mortality risk postdisaster with predisaster mortality levels after excluding direct deaths.

\section{Data analysis}

Age-adjusted mortality rates from 2006 to 2015 were calculated separately for men and women using the 1985 Japanese model population (see online supplementary table S1). ${ }^{24}$ We then compared postdisaster age-adjusted mortality rates (2011-2015) and the average predisaster age-adjusted mortality rates between 2006 and 2010 using $X^{2}$ tests.

In order to assess the temporal trends in excess mortality risk, we compared mortality rates in each month postdisaster (2011-2015) with the average predisaster mortality rate (20062010) using a Poisson regression model with age (0-64, 65-74, 75-84 and 85+ years), city (Soma City or Minamisoma City) and year (baseline (2006-2010), 2011, 2012, 2013, 2014 and 2015 ) as covariates. In order to reduce any seasonal/monthly effect on the data, we constructed regression models for each month (January-December) separately. Our major interests were comparisons between postdisaster years (2011-2015) versus the predisaster baseline with respect to the variable 'year'. Baseline risk was defined as the monthly mortality rate per year from 2006 to 2010, which was also calculated for each month per year (eg, every January across the 5 years). In this regression, to avoid 0 or small numbers of death counts for each age group in each month, the original age groups at 5 -year intervals were reclassified into four age groups (0-64, 65-74, 75-84 and 85+ years). For a detailed explanation of this approach, see online supplementary text $\mathrm{S} 1$.

We performed the cause of death-specific analysis using the same models to evaluate the potential difference in the postdisaster mortality trends by cause of death. We considered the four leading causes of death identified in the first month of the disaster (March 2011). We also separately constructed a regression model for each age group using similar methods to assess how monthly trends in potential postdisaster excess mortality risk differed by age.

We used Stata/MP V.14.1 for all analyses. P Values less than 0.05 were considered statistically significant. R V.3.30 was used to generate graphics. This study was approved by the Ethics Board of Soma Central Hospital (ID: 2016-A1).

\section{RESULTS}

\section{Sample characteristics}

Of the total number of deaths in the predisaster period $(n=6163)$ and in the postdisaster period $(n=7215)$, we excluded 1090 deaths in 2011 as direct deaths. As a result, 6163 (women: 2938, 48\%) deaths in the predisaster period and 6125 (women: $2953,48 \%$ ) deaths in the postdisaster period were included for further analysis. The numbers of indirect and direct deaths by age $(0-39,40-64,65-74,75-84,85+)$, sex (male or female) and year (2006-2015) are shown in table 1.

\section{Trends in age-adjusted mortality rates}

Figure 1 illustrates the yearly trends in age-adjusted total mortality rate per 100000 from 2006 to 2015 for men and women. Comparisons of postdisaster mortality rates with that in the predisaster baseline period (2006-2010) demonstrated a statistically significant decline in 2014 (598 vs 493, p<0.01) and 2015 (598 vs 528, p=0.04) in men and in 2015 in women (300 vs $247, \mathrm{p}=0.03)$.

\section{Predisaster and postdisaster comparison of monthly mortality risks}

Figure 2 shows the estimated relative risks (RRs) of mortality postdisaster in comparison with the predisaster baseline, which were based on month-specific regression models. After adjusting for city and age, the postdisaster mortality risk for both men and women was significantly higher in the first month of the disaster (March 2011) than that in the same month during 


\begin{tabular}{|c|c|c|c|c|c|c|c|c|c|c|c|c|c|}
\hline \multirow[b]{2}{*}{ Age } & \multicolumn{6}{|c|}{ Predisaster period (male) } & \multicolumn{7}{|c|}{ Postdisaster period (male) } \\
\hline & 2006 & 2007 & 2008 & 2009 & 2010 & Total & 2011 & 2012 & 2013 & 2014 & 2015 & $\begin{array}{l}\text { Total indirect } \\
\text { deaths }\end{array}$ & $\begin{array}{l}\text { Total direct } \\
\text { deaths }\end{array}$ \\
\hline 0-39 & 16 & 11 & 19 & 19 & 10 & 75 & 11 & 18 & 10 & 6 & 7 & 52 & 88 \\
\hline $40-64$ & 91 & 97 & 112 & 96 & 116 & 512 & 89 & 92 & 86 & 78 & 95 & 440 & 171 \\
\hline $65-74$ & 120 & 142 & 140 & 130 & 133 & 665 & 96 & 114 & 123 & 109 & 142 & 584 & 104 \\
\hline $75-84$ & 222 & 227 & 225 & 207 & 243 & 1124 & 217 & 220 & 216 & 213 & 204 & 1070 & 121 \\
\hline \multirow{2}{*}{ 85- } & 149 & 158 & 168 & 190 & 184 & 849 & 194 & 167 & 217 & 210 & 238 & 1026 & 38 \\
\hline & \multicolumn{6}{|c|}{ Predisaster period (female) } & \multicolumn{7}{|c|}{ Postdisaster period (female) } \\
\hline Age & 2006 & 2007 & 2008 & 2009 & 2010 & Total & 2011 & 2012 & 2013 & 2014 & 2015 & $\begin{array}{l}\text { Total indirect } \\
\text { deaths }\end{array}$ & $\begin{array}{l}\text { Total direct } \\
\text { deaths }\end{array}$ \\
\hline $0-39$ & 13 & 8 & 10 & 12 & 8 & 51 & 3 & 5 & 7 & 5 & 4 & 24 & 79 \\
\hline $40-64$ & 48 & 40 & 40 & 47 & 42 & 217 & 36 & 27 & 42 & 51 & 36 & 192 & 151 \\
\hline $65-74$ & 60 & 62 & 64 & 68 & 48 & 302 & 38 & 62 & 40 & 58 & 48 & 246 & 126 \\
\hline $75-84$ & 168 & 187 & 172 & 157 & 182 & 866 & 158 & 164 & 151 & 134 & 140 & 747 & 142 \\
\hline $85-$ & 275 & 297 & 323 & 272 & 335 & 1502 & 352 & 307 & 333 & 355 & 397 & 1744 & 70 \\
\hline
\end{tabular}

The counts of direct deaths are shown in the far right column of the table. All direct deaths were observed in 2011.

the predisaster period (March 2006-2010): RR: 2.64, 95\% CI 2.16 to 3.24 ; RR: $2.46,95 \%$ CI 1.99 to 3.03 , respectively. This finding indicates the excess mortality risk due to the indirect effects of the disaster in the first month. The mortality risk dramatically declined from the second month postdisaster (April 2011), and statistical significance was observed in the 10th and 11 th month of the disaster in both men and women. The estimated RRs for the first 12 months of the disaster are shown in online supplementary table $\mathrm{S} 1$.

\section{Cause-specific mortality trends}

In the first month of the disaster (March 2011), when excess mortality risk was identified, the four leading causes of deaths were pneumonia (ICD-10: J12-18, 28\% of the overall mortality; $\mathrm{n}=47$ ), stroke (ICD-10: I60-I69, 15\%; n=25), coronary heart disease (ICD-10: I21-I25, 10\%; $\mathrm{n}=16$ ) and cancer (ICD-10:
C00-97, 9\%; $\mathrm{n}=15)$. In the same month of the predisaster baseline period (March 2006-2010), mortality due to pneumonia, stroke, coronary heart diseases and cancer accounted for 16\% $(n=1049), 14 \%(n=877), 9 \%(n=580)$ and $26 \%(n=1659)$ of the overall mortality, respectively. As for pneumonia, we investigated medical records in the study area and obtained information on 23 of the 47 patients who died from pneumonia. Among them, 15 (65\%) were hospitalised or living in nursing care facilities as of 11 March 2011.

Figure 3 shows the cause-specific trends in the RR of mortality during the postdisaster period. Mortality due to pneumonia, stroke, coronary heart disease and cancer were all significantly higher in the first month of the disaster (March 2011) than in the same month of the predisaster period (March 2006-2010). Estimated cause-specific RRs for the first 12 months from the disaster are presented in online supplementary table S3.

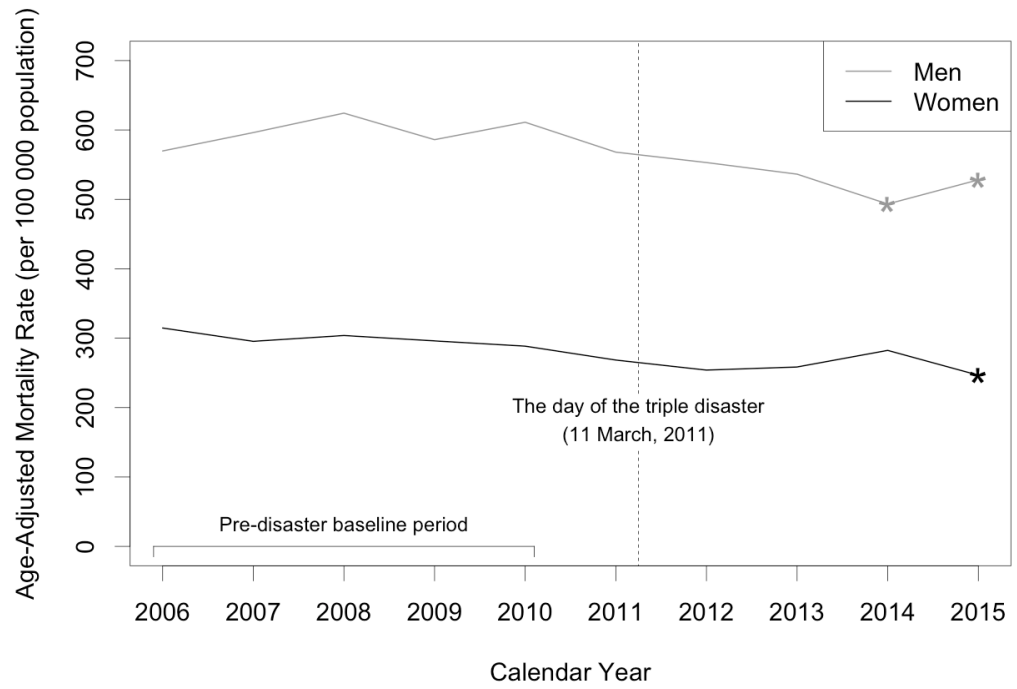

Figure 1 Trends in age-adjusted mortality rates (direct and indirect). The age-adjusted mortality rates after 2011 were compared with those in the control period (2006-2010) using $X^{2}$ tests. The asterisk (*) indicates statistical significance at the 0.05 level compared with the control period. 


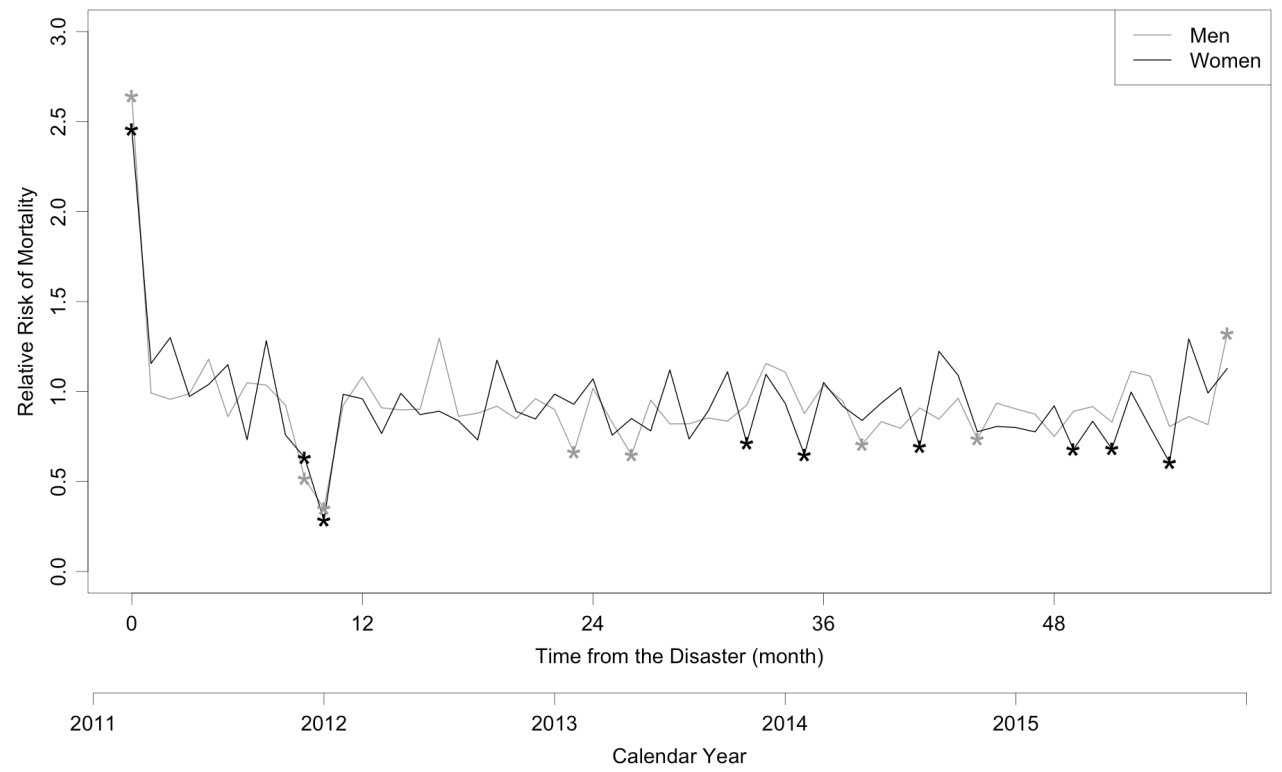

Figure 2 Monthly trends of the relative risks of indirect mortality predisaster and postdisaster. Baseline risk was defined as the monthly mortality rate per year from 2006 to 2010 . The relative risks were adjusted for city and age, and the asterisk (*) indicates statistical significance at the 0.05 level.

\section{Age-specific predisaster and postdisaster comparison of monthly mortality risks}

The age-specific RRs of mortality during the postdisaster period compared with the predisaster baseline are plotted in figure 4. For both sexes, in the first month of the disaster (March 2011), the mortality risks in all age groups were significantly higher than those in the same month of the predisaster baseline period (March 2006-2010). Among women aged 85 years and over, significantly higher mortality risk was also identified in the third month of the disaster (May 2011). The estimated RRs in each age group for the first 12 months of the disaster are shown in online supplementary table S4.

\section{DISCUSSION}

To our knowledge, this is the first study to comprehensively estimate the short-term and long-term indirect health impacts of the triple disaster (earthquake, tsunami and nuclear disaster) in Fukushima through the measurement of excess mortality risk. The results of this study showed that postdisaster excess mortality risk was greatest in the first month of the 5-year postdisaster period. This mortality increase may be due to the indirect health effects of the disaster. Previous studies reported increased burdens of chronic diseases and psychological disorders after the disaster in Fukushima, which are consistent with our findings. ${ }^{25} 26$ In order to mitigate such indirect health
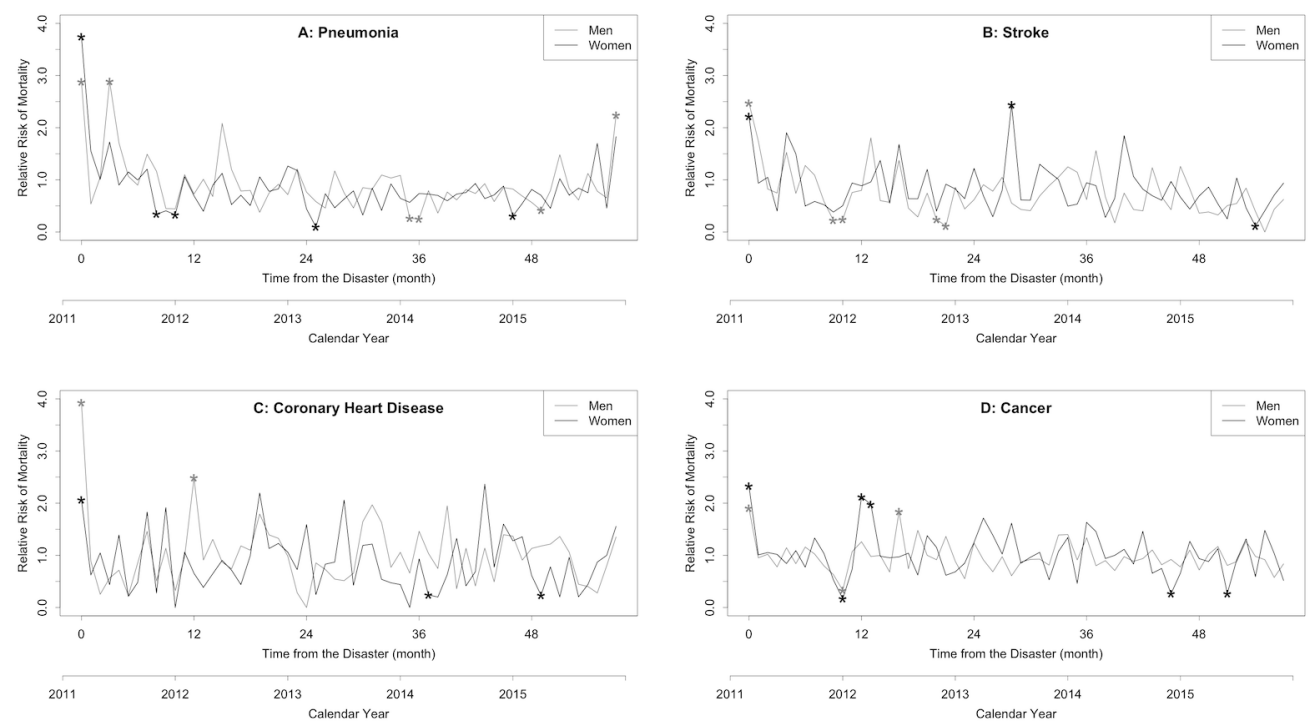

Figure 3 Cause-specific monthly trend of the relative risks of indirect mortality predisaster and postdisaster: (A) pneumonia, (B) stroke, (C) coronary heart disease and (D) cancer. Baseline risk was defined as the monthly mortality rate per year from 2006 to 2010 . The relative risks were adjusted for city and age, and the asterisk $\left(^{*}\right)$ indicates statistical significance at the 0.05 level. 

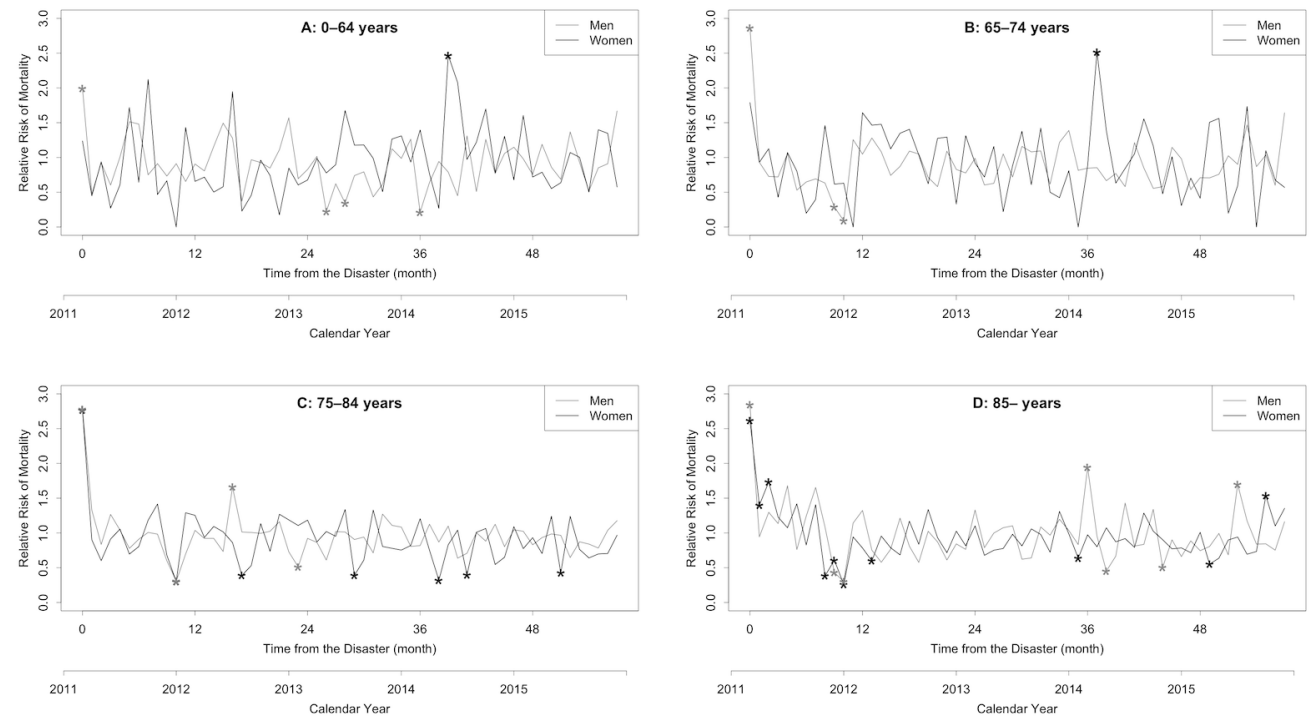

Figure 4 Age-specific monthly trends of the relative risks of indirect mortality predisaster and postdisaster: (A) 0-64 years, (B) 65-74 years, (C) 75-84 years and (D) 85- years. Baseline risk was defined as the monthly mortality rate per year from 2006 to 2010 . The relative risks were adjusted for city, and the asterisk $\left({ }^{*}\right)$ indicates statistical significance at the 0.05 level.

effects of disasters, initial public health support, such as facilitating community development, restoring livelihoods, providing psychosocial support to inform people and mobilising community partnership, is important. ${ }^{27-29}$ This study also suggested the importance of initial public health support, particularly within the first month postdisaster, in reducing indirect health effects of a disaster.

The increase in mortality risks persisted for 3 months after the disaster among women 85 years or older (figure 4 ). This persistent increase in mortality risk is consistent with that observed after Hurricane Katrina. ${ }^{18}$ Our findings suggest that mortality risk due to the indirect health effects of the disaster may be more severe and persistent among the elderly than among younger groups. This larger effect among the elderly may be explained by their increased risks of impaired physical mobility, diminished sensory awareness, poor chronic health conditions, and social and economic limitations, ${ }^{30}$ which may hinder their adaptability after disasters. ${ }^{13}$ Several studies reported increased health burdens among the elderly associated with the indirect health effects of a disaster. ${ }^{31} 32$ Our findings suggest that the public health support to mitigate the indirect health effects of disasters may be more important among the elderly than in the general population.

The four leading causes of death included pneumonia, coronary heart disease, stroke and cancer. These increases in mortality risk after disasters are consistent with past studies. ${ }^{33} 34$ Patients with chronic conditions such as cancer and those with acute health conditions such as pneumonia, coronary heart disease and stroke are dependent on medical care, which may explain their vulnerability to the impacts of a disaster, including the loss of access to medical care, environmental change, and physical and psychological stress.

In particular, pneumonia accounted for 28\% (47/165) of the deaths during the first month after the earthquake. A previous study hypothesised that postdisaster increases in pneumonia were caused by the swallowing of dust and water carried by the tsunami. ${ }^{33}$ However, in our findings, more than half of the patients who died from pneumonia were in inpatient medical facilities at the time of the earthquake, making them unlikely to be directly affected by the tsunami. A previous study on patients with pneumonia after the disaster suggested that most cases of pneumonia were aspiration pneumonia acquired in a nursing home, which was associated with low patient activities of daily living status. ${ }^{34}$ Deterioration of primary care after disasters makes it difficult to provide adequate oral care in order to reduce the mortality rate of aspiration pneumonia in such cases. $^{35}$

In contrast to the first month after the disaster, there were no significant increases in the mortality risks in the second month and thereafter, although previous disaster studies reported exacerbation of chronic diseases in affected areas. ${ }^{2526}$ There are a few possible explanations. First, temporary housing was provided to reduce the mortality risk due to psychological stress ${ }^{20}$ and social isolation ${ }^{36}$ after the triple disaster: housing assignments in temporary housing were based on pre-earthquake addresses to maintain a sense of community. Second, health facilities were at least partially restored in the affected areas by the second postdisaster month and onwards. These elements could have mitigated the expected increase in mortality by exacerbation of chronic diseases. ${ }^{37}$ For effective long-term support after disasters, further monitoring the effectiveness of individual measures will be essential.

It is also of note that the increased mortality risks did not persist over the 5 years since the triple disaster. The series of disasters, particularly the nuclear disaster at Fukushima Daiichi Nuclear Power Plant, has led to serious concerns about health problems among residents in the affected area. Although past studies showed that radiation exposure among residents of the study area was not high enough to cause health problems, ${ }^{38} 39$ fear for health damage due to radiation exposure remains. ${ }^{40}$ There was no increase in cancer mortality rates observed in this study; however, the 5-year study period is likely not long enough to assess the potential carcinogenic effects of radiation. ${ }^{41}$ Therefore, we are not able to conclude that cancer incidence due to radiation exposure has not increased in this area. A longterm analysis of the exposed population cohort will be required in order to evaluate the effects of radiation exposure on carcinogenesis. 


\section{Limitations}

This study has several limitations. First, the estimated indirect mortality risk in the latter period should be interpreted with caution. As shown in figure 1, the age-adjusted mortality rate has been decreasing throughout the study period. This decreasing trend, in line with age-adjusted mortality rates in Japan as a whole, ${ }^{42}$ might be explained by the reduction of cancer mortality, new technologies or improved management of chronic diseases. ${ }^{43}$ The long-term indirect health effects of the disaster on mortality risk might be counterbalanced by the decreasing mortality trends. Second, in the present study, mortality data were based on the Basic Resident Registers, and residents who moved their registrations to outside the study area were excluded. Therefore, the estimation of mortality risk in this study may be biased due to sampling limitations. Finally, the causes of death listed in the vital registration are occasionally inaccurate and incomplete, particularly in the ageing population. ${ }^{45}$ In the present study, we attempted to minimise such bias by checking medical records and other sources.

\section{CONCLUSION}

In the 5 years since the 2011 triple disaster in Japan, mortality risk, excluding direct health damage from the disaster, was highest in the first month after the disaster. This excess risk of death is attributed to the indirect health impacts of the triple disaster. The increased mortality was more severe and long-lasting among the elderly. Early public health support for the elderly, including facilitating community development, restoring livelihoods and providing psychosocial support, preferably within a month of a disaster, is one of the most important factors in reducing the indirect health effects of a disaster.

\section{What this study adds}

- We clarified that the postdisaster mortality risk was significantly higher in the first month of the disaster compared with that during the predisaster period (20062010), which suggests excess mortality risk due to the indirect health effects of the disaster.

- The indirect health effects of a disaster may be more severe and persistent among the elderly than among younger groups. Early public health support, especially for the elderly, such as facilitating community development, restoring livelihoods, providing psychosocial support to inform people and mobilising community partnerships, is an important factor for reducing the indirect health effects of a disaster.

\section{What is already known on this subject}

- Although the health effects of natural and man-made disasters can be both direct and indirect, there is little evidence on the indirect health effects of a disaster.

- The 2011 triple disaster (earthquake, tsunami and nuclear disaster) in Fukushima resulted in the opportunity to assess excess mortality risk due to the indirect health effects of the disaster.

\section{Author affiliations}

'Internal Medicine, Soma Central Hospital, Fukushima, Japan

${ }^{2}$ Division of Social Communication System for Advanced Clinical Research, Institute of Medical Science, The University of Tokyo, Tokyo, Japan

${ }^{3}$ Department of Epidemiology and Biostatistics, School of Public Health, Imperial College London, London, UK
${ }^{4}$ Department of Global Health Policy, Graduate School of Medicine, The University of Tokyo, Tokyo, Japan

${ }^{5} \mathrm{Global}$ Public Health Unit, School of Social and Political Science, University of Edinburgh, Edinburgh, UK

${ }^{6}$ Department of Research, Minamisoma Municipal General Hospital, Fukushima, Japan

${ }^{7}$ Department of Surgery, Minamisoma Municipal General Hospital, Fukushima, Japan ${ }^{8}$ Department of Health and Human Security, Graduate School of Medicine, The University of Tokyo, Tokyo, Japan

${ }^{9}$ Research Institute of Innovative Medicine, Tokiwa Foundation, Fukushima, Japan

${ }^{10}$ Center for regional cooperation, Iwaki Meisei University, Fukushima, Japan

${ }^{11}$ Department of Medical Research, Medical Governance Research Institute, Tokyo, Japan

Acknowledgements We thank the staff of the Soso Public Health and Welfare Office (especially Mr Shinichi Ogata), Soma City Office, and Minamisoma City Office as well as Mr Toshinari Tsukui, Mr Masatsugu Tanaki, Mr Masatsugu Endo, Dr Hidekiyo Tachiya, Mr Katsunobu Sakurai, Mr Toshihiko Atarashi and Ms Masako Mori for data collection and management. We also pray sincerely for the repose of those who perished in the disaster.

Contributors TM, MI, KS, SK and MK developed the study concept and design. TM, SO, AO, YS, KY and MT collected and managed the data, including quality control. SN and SG provided statistical advice on the study design and analysed the data. TM, $\mathrm{SN}$ and $\mathrm{CL}$ drafted the manuscript, and all authors contributed substantially to its revision. SN and TM take responsibility for the paper as a whole.

Competing interests $\mathrm{MI}$ is the beneficiary of a financial contribution from the AXA Research Fund as chair holder of the AXA Department of Health and Human Security, Graduate School of Medicine, The University of Tokyo. The AXA Research Fund has no role in this work. The authors declare no other conflicts of interest.

Patient consent Detail has been removed from this case description/these case descriptions to ensure anonymity. The editors and reviewers have seen the detailed information available and are satisfied that the information backs up the case the authors are making.

Ethics approval Soma Central Hospital.

Provenance and peer review Not commissioned; externally peer reviewed.

(c) Article author(s) (or their employer(s) unless otherwise stated in the text of the article) 2017. All rights reserved. No commercial use is permitted unless otherwise expressly granted.

\section{REFERENCES}

1 Mathers CD, Stevens GA, Boerma T, et al. Causes of international increases in older age life expectancy. Lancet 2015;385:540-8.

2 Cutter SL, Ismail-Zadeh A, Alcántara-Ayala I, et al. Global risks: Pool knowledge to stem losses from disasters. Nature 2015;522:277-9.

3 Watts N, Adger WN, Agnolucci P, et al. Health and climate change: policy responses to protect public health. Lancet 2015:386:1861-914.

4 Andrew MK, Mitnitski AB, Rockwood K, et al. frailty and mortality in elderly people. PloS one 2008; 3:e2232.

5 Kennedy P, Ressler E. Handbook of disaster research: Springer Science \& Business Media, 2009.

6 Aitsi-Selmi A, Egawa S, Sasaki H, et al. The Sendai Framework for Disaster Risk Reduction: Renewing the Global Commitment to People's Resilience, Health, and Well-being. Inter J Disaster Risk Sci 2015;6:164-76.

7 Morita T, Tsubokura M, Furutani T, et al. Impacts of the 2011 Fukushima nuclear accident on emergency medical service times in Soma District, Japan: a retrospective observational study. BMJ Open 2016;6:e013205.

8 Hayano RS, Adachi R. Estimation of the total population moving into and out of the $20 \mathrm{~km}$ evacuation zone during the Fukushima NPP accident as calculated using "Auto-GPS" mobile phone data. Proc Jpn Acad Ser B Phys Biol Sci 2013;89:196-9.

9 Dominici F, Levy Jl, Louis TA. Methodological challenges and contributions in disaster epidemiology. Epidemiol Rev 2005;27:9-12.

10 Shoaf K. Organizing the health sector for response to disasters. Cien Saude Colet 2014;19:3705-15.

11 Rofi A, Doocy S, Robinson C. Tsunami mortality and displacement in Aceh province, Indonesia. Disasters 2006;30:340-50

12 Wingate MS, Perry EC, Campbell PH, et al. Identifying and protecting vulnerable populations in public health emergencies: addressing gaps in education and training. Public Health Rep 2007;122:422-6.

13 Fernandez LS, Byard D, Lin CC, et al. Frail elderly as disaster victims: emergency management strategies. Prehosp Disaster Med 2002;17:67-74.

14 Few R, Ahern M, Matthies F, et al. Floods. health and climate change: a strategic review: Tyndall Centre for Climate Change Research Norwich 2004.

15 Jhung MA, Shehab N, Rohr-Allegrini C, et al. Chronic disease and disasters medication demands of Hurricane Katrina evacuees. Am J Prev Med 2007;33:207-10. 
16 Kario K, McEwen BS, Pickering TG. Disasters and the heart: a review of the effects of earthquake-induced stress on cardiovascular disease. Hypertens Res 2003;26:355-67.

17 Kouadio IK, Aljunid S, Kamigaki T, et al. Infectious diseases following natural disasters: prevention and control measures. Expert Rev Anti Infect Ther 2012;10:95-104.

18 Stephens KU, Grew D, Chin K, et al. Excess mortality in the aftermath of Hurricane Katrina: a preliminary report. Disaster Med Public Health Prep 2007;1:15-20.

19 Ching PK, de los Reyes VC, Sucaldito MN, et al. An assessment of disaster-related mortality post-Haiyan in Tacloban City. Western Pac Surveill Response J 2015:6:34-8.

20 Miller AC, Arquilla B. Chronic diseases and natural hazards: impact of disasters on diabetic, renal, and cardiac patients. Prehosp Disaster Med 2008;23:185-94.

21 Burkle FM, Greenough PG. Impact of public health emergencies on modern disaster taxonomy, planning, and response. Disaster Med Public Health Prep 2008;2:192-9.

22 Uscher-Pines L. But for the hurricane: measuring natural disaster mortality over the long-term. Prehosp Disaster Med 2007;22:149-51.

23 Arnold JL. Disaster medicine in the 21st century: future hazards, vulnerabilities, and risk. Prehosp Disaster Med 2002;17:3-11.

24 Hori M, Matsuda T, Shibata A, et al. Cancer incidence and incidence rates in Japan in 2009: a study of 32 population-based cancer registries for the Monitoring of Cancer Incidence in Japan (MCIJ) project. Jpn J Clin Oncol 2015;45:884-91.

25 Morita T, Tanimoto T, Hori A, et al. Alcohol use disorder due to social isolation after a nuclear disaster in Fukushima. BMJ Case Rep 2015;2015:bcr2015209971.

26 Nomura S, Blangiardo M, Tsubokura M, et al. Postnuclear disaster evacuation and chronic health in adults in Fukushima, Japan: a long-term retrospective analysis. BMJ Open 2016:6:e010080.

27 Logue JN. The public health response to disasters in the 21st century: reflections on Hurricane Katrina. J Environ Health 2006:69:926.

28 Reyes G, Elhai JD. Psychosocial interventions in the early phases of disasters. Psychotherapy: Theory, research, practice. Training 2004:41:399.

29 Dodge GR. In defense of a community psychology model for international psychosocial intervention. Handbook of international disaster psychology 2006; 1:51-64.

30 Aldrich N, Benson WF. Disaster preparedness and the chronic disease needs of vulnerable older adults. Prev Chronic Dis 2008;5:A27.

31 Sharma AJ, Weiss EC, Young SL, et al. Chronic disease and related conditions at emergency treatment facilities in the New Orleans area after Hurricane Katrina. Disaster Med Public Health Prep 2008;2:27-32.
$32 \mathrm{Heo} \mathrm{JH,} \mathrm{Kim} \mathrm{MH,} \mathrm{Koh} \mathrm{SB,} \mathrm{et} \mathrm{al.} \mathrm{A} \mathrm{prospective} \mathrm{study} \mathrm{on} \mathrm{changes} \mathrm{in} \mathrm{health} \mathrm{status}$ following flood disaster. Psychiatry Investig 2008;5:186-92.

33 Uchimura M, Kizuki M, Takano T, et al. Impact of the 2011 Great East Japan Earthquake on community health: ecological time series on transient increase in indirect mortality and recovery of health and long-term-care system. J Epidemiol Community Health 2014;68:874-82.

34 Shibata Y, Ojima T, Tomata Y, et al. Characteristics of pneumonia deaths after an earthquake and tsunami: an ecological study of 5.7 million participants in 131 municipalities, Japan. BMJ Open 2016;6:e009190.

35 Bassim CW, Gibson G, Ward T, et al. Modification of the risk of mortality from pneumonia with oral hygiene care. J Am Geriatr Soc 2008;56:1601-7.

36 Holt-Lunstad J, Smith TB, Layton JB. Social relationships and mortality risk: a metaanalytic review. PLoS Med 2010;7:e1000316.

37 Nishikawa Y, Fukuda Y, Tsubokura M, et al. Managing Type 2 Diabetes Mellitus through Periodical Hospital Visits in the Aftermath of the Great East Japan Earthquake Disaster: A Retrospective Case Series. PLoS One 2015;10:e0125632.

38 Tsubokura M, Kato S, Nihei M, et al. Limited internal radiation exposure associated with resettlements to a radiation-contaminated homeland after the Fukushima Daiich nuclear disaster. PLoS One 2013;8:e81909.

39 Tsubokura M, Kato S, Morita T, et al. Assessment of the Annual Additional Effective Doses amongst Minamisoma Children during the Second Year after the Fukushima Daiichi Nuclear Power Plant Disaster. PLoS One 2015;10:e0129114.

40 Shibuya K, Gilmour S, Oshima A. Time to reconsider thyroid cancer screening in Fukushima. Lancet 2014;383:1883-4.

41 Ron E, Lubin JH, Shore RE, et al. Thyroid cancer after exposure to external radiation: a pooled analysis of seven studies. Radiat Res 1995;141:259-77.

42 Ministry of Health LaW. Situation of mortality from all causes. http://www.mhlw.go.jp/ toukei/saikin/hw/jinkou/other/05sibou/02.html

43 Katanoda K, Hori M, Matsuda T, et al. An updated report on the trends in cancer incidence and mortality in Japan, 1958-2013. Jpn J Clin Oncol 2015;45:390-401.

44 García-Lizana F, Sarría-Santamera A. New technologies for chronic disease management and control: a systematic review. J Telemed Telecare 2007:13:62-8.

45 Mieno MN, Tanaka N, Arai T, et al. Accuracy of Death Certificates and Assessment of Factors for Misclassification of Underlying Cause of Death. J Epidemiol 2016;26:191-8. 